\title{
A Cost-Benefit Analysis of Early Childhood Hygiene Interventions in Uzbekistan
}

\author{
Raushan ATANIYAZOVA ${ }^{*}$, Jahongir NEGMATOV ${ }^{* *}$, Ziyodullo PARPIEV ${ }^{* * *}$
}

\begin{abstract}
This paper applies cost-benefit analysis (CBA) technique to estimate the effectiveness of hand hygiene and oral health interventions in Uzbekistan for children of kindergarten age (3-6 years old). Our primary objective in this study is to apply CBA framework to investigate economic viability of hand hygiene and oral health interventions on respiratory diseases (influenza, bronchitis, pneumonia), intestinal diseases (diarrhea, hepatitis $A$, and helminthiasis), and dental caries and stomatitis. Though it is often difficult to attribute a specific hygiene intervention to a reduction in specific illness, our study shows that prevention of disease through hygiene promotion is cost-effective. To be the most effective, however, hygiene interventions should be accompanied by education and awareness-raising of teachers, parents and children.
\end{abstract}

Keywords: Cost-Benefit Analysis, Hygiene, Hand Washing

JEL Code Classification: D61, 115

\footnotetext{
* German Agency for International Development (GIZ) in Uzbekistan. E-mail:raushan.ataniyazova@giz.de

***anking and Finance Academy, Tashkent, Uzbekistan. E-mail: jnegmatov@wiut.uz

*** Westminster International University in Tashkent (WIUT). E-mail: zparpiev@wiut.uz

Copyright $\odot, 2014$ International Ataturk Alatoo University.
} 


\section{Introduction}

Cost-benefit analysis ( $C B A)$ is one of the most widespread tools to estimate the effectiveness of policy interventions in different settings. CBA has proved useful in assessing the impact of a policy or program in many areas. In a typical CBA, the goal is to select projects with the highest net benefits: total social benefits less total social costs. In doing so, CBA attempts to monetize all cost and benefit cash flows that accrue following the health intervention. Cost of intervention includes the cost of equipment, trainings, as well as cost of running a program. Total societal economic benefit is measured by summing up (a) health sector benefits due to avoided illness; (b) treatment expenses saved due to avoided illness; and (c) value of parents' workdays lost using actual or average wage rates, etc.

Our primary objective in this study is to apply CBA framework to investigate economic viability of hand hygiene and oral health interventions on respiratory diseases (influenza, bronchitis, pneumonia), intestinal diseases (diarrhea, hepatitis A, and helminthiasis), and dental caries and stomatitis in the kindergarten age (3-6 years old) children. To our knowledge, this kind of work has not been done previously. Based on the results of the study, we intend to develop a set of recommendations on improving hand hygiene and oral health.

This paper is organized as follows. Section 2 describes child mortality and morbidity situation in Uzbekistan. Section 3 surveys available literature on the impacts of health promotion and disease preventive interventions on young children. Section 4 describes the data and methodology employed in this paper. It also outlines the principles of CBA. Section 5 presents descriptive analysis of survey data conducted to collect data on 105 households цшер children of kindergarten age. Section 5 presents CBA results. Section 6 concludes and outlines policy recommendations.

\section{Child Morbidity and Mortality in Uzbekistan}

Hand and oral cavity hygiene is on the agenda of most developed countries, where personal hygiene and infrastructure means are readily available. The inhabitants of less developed countries, on the other hand, must contend with an inadequate public health infrastructure, lack of education programs, and economic limitations in obtaining hygiene products. Therefore, as a rule, less developed countries carry a greater burden of morbidity and mortality from infectious illnesses. World Bank estimates that by 2010 approximately 1 billion individuals globally lacked adequate water supply and more than 2 billion lacked access to adequate sanitation.

In Uzbekistan, unlike in many developing countries with similar income per capita, pre-school education is well developed. Almost all pre-school facilities are built to meet specific requirements such as easy-to-use toilets and sinks, and have access to centralized or local heating and water supply systems. 
In addition, a comprehensive legislation for effective implementation of hand hygiene and oral health norms is developed. Specifically, more than 30 legislative norms regulate the organization of education in pre-schools and schools, with a particular attention to education on hygiene practices. Within the healthcare system, Centers of State Sanitary and Epidemiological Surveillance (CSSES) are responsible for preventive medicine. In particular, CSSES requires that games and sports equipment, furniture, computer equipment, games, toys, hygiene and child care tools, detergents and disinfectants in pre-schools should satisfy the sanitaryepidemiological norms. CSSES carries out regular sanitary inspections over the compliance with sanitary norms and hygienic standards in pre-school facilities. Norms and rules also regulate the vaccination against preventable diseases for children of kindergarten age.

The importance of reducing morbidity and mortality rates among children under 5 is clearly understood by policymakers at all levels. One of the nationalized Millennium Development Goals (MDG) - Goal 4 - is formulated in terms of reducing under-five child mortality rate by two thirds by 2015 .

There has been good progress in improving situation in young children's health in Uzbekistan. According to 2006 Multiple Indicator Cluster Survey (MICS) the child mortality and child malnutrition has significantly declined. The survey also found that over $80 \%$ of children are fully vaccinated prior to their first birthday; and $84 \%$ of mothers breast-feed their children until the age of one year (UNICEF 2007).

The information on causes of mortality and morbidity is scarce. WHO, for example, reports distribution of years lost due to communicable and non-communicable diseases, as well as due to injuries only for 2008. According to the statistics, $34 \%$ of years lost happened because of communicable diseases, while share of noncommunicable diseases and injuries amounted to 55 and $10 \%$, respectively.

Official statistics also reports modest rates of disease incidences. According to CSSES, acute respiratory infections accounted for $76.2 \%$ of all registered diseases in 2010, while acute intestinal infections, such as diarrhea, and hepatitis A - 7.1\% and $7.0 \%$, respectively. 11.7 cases of acute respiratory infections per 1,000 people were registered. Incidence of the disease among children of age 3 to 5 was significantly higher, at 37.2 cases per 1,000 children. In Tashkent city, this indicator was 15.2, one of hepatitis A was 1.05 per 1,000 people. Among children aged 3to5, the rate was 6.78 , while in Tashkent it was 4.3 per 1,000 children of the corresponding age.The incidence of acute intestinal infections was 1.2 per 1,000 people; while the same indicator for children aged 3-5 was 1.44. This indicator was highest in Tashkent -1.86 cases per 1,000 children.

Causes of under age 5 child mortality differ at different ages. If in the neonatal period after-birth complications (prematurity, asphyxia, infection and congenital diseases) cause majority of child mortality, pneumonia and diarrhea take over in later period and become the most important causes of child deaths. Health 
outcomes in pre-school age (between 3 and 6) are strongly associated with morbidity trends in early childhood.

Though we could not find statistical data on oral cavity diseases, such as caries and stomatit is, there is no doubt that majority of pre-school age children suffer from these diseases too. One of the internal documents of the Ministry of Health states that $84 \%$ children under 7 suffer from caries. Though this appears to be a reference to the prevalence of caries, not its incidence, it implies a high rate of caries incidence.

Proper hand hygiene and oral health can play an important role in reducing both morbidity and mortality rates among children. International evidence suggests that targeted interventions to improve hygiene might be one of the most effective instruments, since prevention of diseases is much more cost-effective than their treatment. If these interventions succeed in bringing down the incidence of acute respiratory and intestinal diseases, this would help reduce costs of illnesses.

\section{Literature Review}

Hygiene promotion is an essential component of health intervention programs for the reduction of transmission and resultant outcomes of diseases. While countries that were able to improve public hygiene considerably decreased their mortality and morbidity rates due to infectious diseases, many other countries missed this opportunity.

Hands are agents that that directly or indirectly transmit bacterial and viral pathogens from one person to another. Microbiologists have identified respiratory pathogens on hands (Hendley, Wenzel and Gwaltney 1973; Reed 1975; Gwaltney, Moskalski and Hendley 1978, 1980; Ansari, et al. 1991). Hands that have been in contact with faeces and nasal excretions and other bodily fluids, if not washed properly subsequently, can be a source of large number of germs (Bloomfield and Scott 2003). Studies have repeatedly shown that though soap is widely available in developing, as well as developed countries, it is mostly used for bathing and washing clothes. Thus the challenge with promotion of hand washing hygiene is that, in order to be effective and long-lasting, it must change the behavior of children and their parents.

Although many hygiene practices including water supply and sanitation help prevent the diseases, hand washing with soap remains effective (Curtis and Cairncross 2003), feasible (Khan 1982; Stanton and Clemens 1987, Pinfold and Horan 1996; Curtis, et al. 2001) and cost-effective tool in developing countries (J. Borghi, et al. 2002, Curtis, Cairncross and Yonli 2000). While the impact of water supply and sanitation on child mortality has been impressive, hand washing turned out to have even a greater impact on reducing the mortality and morbidity rates (Cairncross 2003, Esrey et al. 1985). Empirical evidence suggests that many infections are preventable via hand washing. 
The importance of hand washing in the prevention of diarrheal diseases has been underlined by a recent systematic review showing that the simple act of washing one's hands with soap can reduce the risk of diarrhea by nearly half, and of lifethreatening diarrhea by more than half, in both developed and developing countries (Curtis and Cairncross 2003). The study conducted a meta-analysis of 17 published articles studying the link between hand washing and diarrhea mostly in developing countries. They show that washing hands with soap can reduce the risk of diarrheal diseases by $42-47 \%$ on average.

Moreover, hand washing has also beneficial effects on the reduction of other widespread disease of children in developing countries - the acute respiratory tract infections (ARI). ARI cause at least 2 million deaths a year (Guerrant and Blackwood 1999, WHO 2002) and is a leading cause of child morbidity and mortality rates worldwide and of the disability-adjusted life years lost (DALYs) (Murray and Lopez 1997). In the cross section of 42 countries, $21 \%$ of mortality causes were pneumonia (Black, Morris and Bryce 2003). There is growing evidence from developed countries that hand washing can substantially reduce the risk of respiratory tract infection (Master, et al. 1997; St Sauver, et al. 1998; Dyer, et al. 2000; and Ryan, et al. 2000). Most of these studies on the control of ARI is about promoting appropriate care-seeking diarrhea for sick children, rather than reducing transmission.

Earlier most comprehensive study that shows that hand washing could reduce the risk of respiratory infections by $45 \%$ among young recruits under training was a study by the US Navy (Ryan et al. 2001). The sample size was very large (more than 44000 in each exposure group) which lends additional weight to the findings. Military discipline helped to ensure compliance. However, many specialists still see measures like hand washing for the prevention of faecally transmitted diseases such as diarrhea as completely distinct from the control of infections transmitted in airborne droplets, when 'coughs and sneezes spread diseases'.

Figure 1 shows the average reductions in diarrhea incidence found to be associated with hygiene, sanitation and water supply interventions in several literature reviews. The impact of "real world" interventions varies widely in response to local factors such as which pathogens are contributing to disease and the relative contribution of different transmission routes.

It is evident that median risk reduction for diarrhea due to hand washing was around $45 \%$. The reduction in disease incidence was even higher if hand washing campaign was accompanied with overall hygiene promotion and sanitation.

Luby et al. (2005) conduct randomized control trial and estimate the effect of hand washing on pneumonia. They show that children younger than 5 years in households that received plain soap and hand washing promotion had a $\mathbf{5 0 \%}$ lower incidence than controls ( $95 \% \mathrm{Cl}-65 \%$ to $-34 \%)$. 


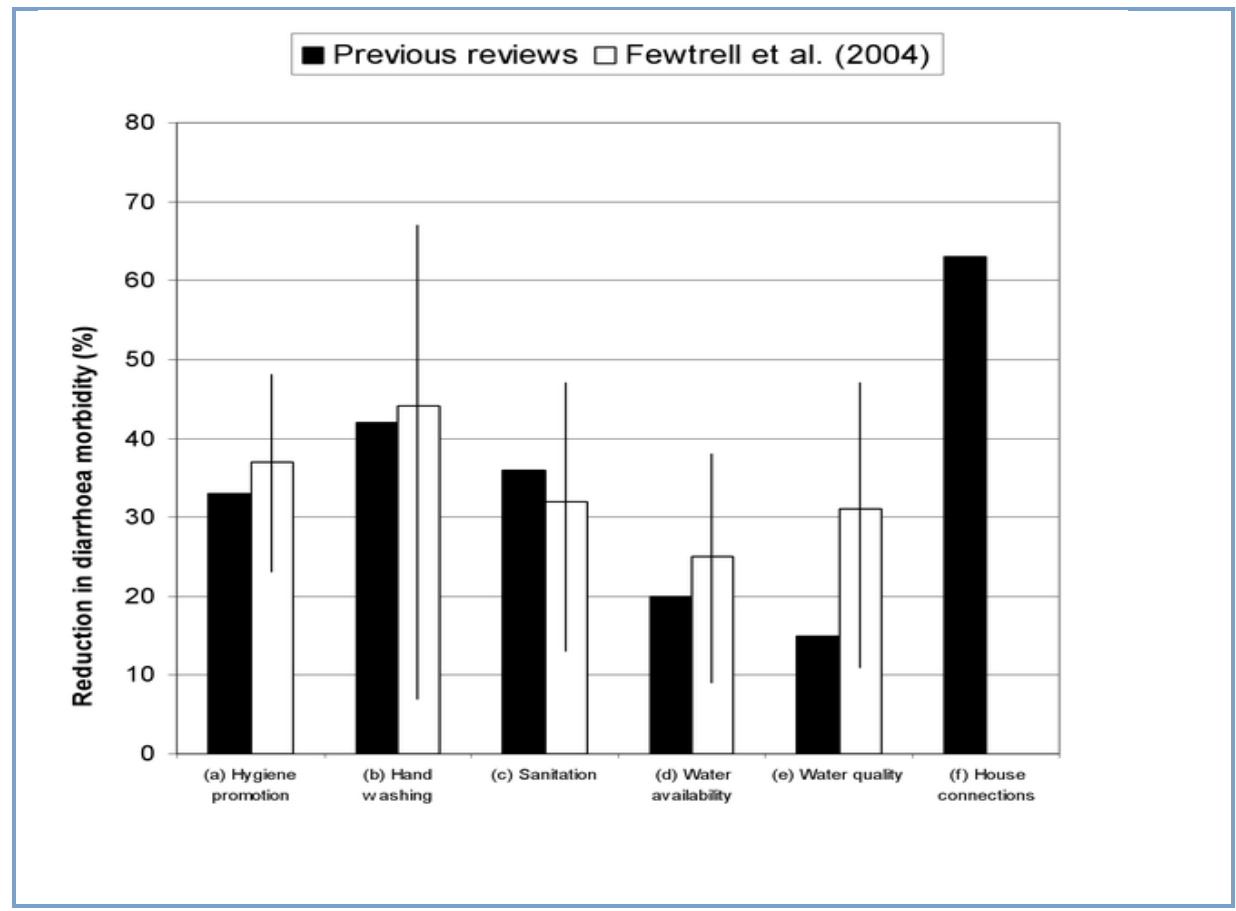

Figure 1. Average Reductions in Diarrhea Incidence Associated with Hygiene, Sanitation and Water Supply Interventions

Some authors have tested the health impact of more than one intervention. The recent large randomized control trial in Pakistan showed that household water treatment resulted in a 53-59\% reduction in the weekly diarrhea prevalence and hand washing with soap in a $45 \%$ reduction. A combination of both interventions however resulted only in a $50 \%$ reduction in diarrhea. The authors suggested that introducing two interventions simultaneously does not allow their optimal combined use as behavior change is best achieved through simple messages.

Early childhood caries is prevalent in both developed (Holt, et al. 1996) and developing (Ye, Feng and Liu 1999) countries. Depending on identified source of caries, there are basically two schools of thought on caries. The first school recommends drastic decrease in sugar intake, while the second one argues that sugar intake is not the main determinant of caries, but use of fluoride is. This school of thought advocates for frequent and regular tooth brushing as the most efficient preventive measure against caries in young children.

Harris, et al. (2004) review 77 studies on caries published between 1966 and 2002. Out of 77, 7 are the so-called intervention studies that measure the impact of a particular intervention on the prevalence of caries. 5 of them found that caries 
declined in treatment groups compared to test groups. In particular, Schwarz, Lo and Wong (1998)showed that introduction of daytime toothbrushing after lunch in kindergartens decreased prevalence of caries from $25 \%$ to $20 \%$ in test group and $12 \%$ in control group. Recent study by Pita-Fernández, et al. (2010)shows that toothbrushing has a significant impact on oral health. In particular, they find that children who never brush their teeth have a $40 \%$ rate of early caries, while those who brush their teeth several times a day have $15.3 \%$, a reduction of almost $25 \%$.

Empirical evidence shows that health benefits of hand and hygiene go beyond major diseases. For example, ascaris and other intestinal worms are known to be associated with poor sanitation, but a recent review by Fung and Cairncross (2009) found evidence that hand washing with soap can also help to prevent transmission of ascariasis.

One of the most difficult results that hygiene interventions seek to achieve is behavioural change. The literature on this aspect of health interventions is still emerging and relatively scarse. It has only recently become clear to health professionals that emotional levers ("Clean hands feel good") change people's health behaviour more effectively than cognitive statements ("Dirty hands cause disease"). Curtis et al. (2009) show that it is important to invest in formative research, testing, and evaluation, to tailor the messages to local people's beliefs and aspirations. If health workers can divest themselves of the unsubstantiated belief that health considerations motivate behaviour, they can become a more effective force for hygiene behaviour change.

In fact, the benefits to health of improving hygiene are far greater than implied by disease-specific statistics. In the early 1900s, sanitary engineers in the US and Germany identified the "Mills-Reincke phenomenon." Their studies showed that for every death from typhoid fever averted by water supply improvements, two to three deaths from other causes, including tuberculosis, pneumonia, and other causes of child mortality, were also avoided (Sedgwick and Macnutt, 1908).

Modern studies have shown that frequent bouts of diarrhea and intestinal parasitosis are important causes of malnutrition, which renders children more susceptible to other diseases. For example, when malnourished children are recovering from an episode of diarrhoea, they are unusually susceptible to pneumonia; this diarrhoea-induced susceptibility may be associated with as much as $26 \%$ of all childhood pneumonia episodes (Schmidt et al., 2009).

The disease burden weighs heavily on both households and health systems. It has been estimated that the health costs alone amount to some US\$340 million for households lacking water supply and sanitation and US\$7 billion for national health systems (Hutton and Haller, 2004). The household burden weighs most heavily upon the poor, but well-conceived sanitation and water programmes can weaken the link between poverty and disease (Genser et al., 2008) and so contribute to health equity. 
Many studies have shown that hygiene interventions are highly cost-effective. When all costs and benefits associated with the hygiene and sanitation promotion are accounted for, many hygiene interventions yield a net benefit in the range US\$3-46 per dollar invested (Hutton and Haller, 2004; Laxminarayan et al., 2006; Acharya and Paunio, 2008; Churchill et al., 1987 and Hutton et al., 2007).

These benefits are substantive at macroeconomic as well as household levels, as shown by Acharya and Paunio (2008), and by a study for the Commission on Sustainable Development. This second study found that the per capita GDP growth of poor countries with improved access to water and sanitation was much higher than that of equally poor countries without improved access $(3.7 \%$ and $0.1 \%$, respectively) (Sanctuary et al., 2004).

\section{Data and Methodology}

\subsection{Cost Related Data and Methodology}

Cost related data is mainly based on the table data kindly provided by GIZ GmbH Tashkent Office. It covers the hand hygiene and oral health interventions undertaken by GIZ GmbH Tashkent Office in collaboration with the Ministry of Public Education and the Ministry of Health of the Republic of Uzbekistan within 'Your Safety is in Your Clean Hands' project. The table is broken down into costs of hand hygiene and oral health promotion activities. The data also shows the approximate number of children covered for each intervention.

A few transformations are made to the cost data for further processing. First, the cost for each intervention in a group is assigned an equal value within a group. Second, the same has been done for the number of children covered under each intervention. Both of these transformations do not alter the total cost of interventions and the number of children as costs for each intervention and children covered add up to the cost and number of children for a group.Third, effective periods of interventions differ, adjustments are made to equalize them. Interventions are grouped into a hygiene promotion and hygiene means and the FAQ for this purpose. Hygiene promotion interventions are expected to have an effective period of one year, while hygiene means and the FAQ interventions are assumed to last for a period of six months. To equalize effective periods, costs related to hygiene means and the FAQ are double counted. Fourth, as effective periods are annualized, assumptions regarding the cost timing are mad : all initial costs will be incurred at the beginning of a year of 2012 plus to-be-double-counted hygiene means and the FAQ costs will be incurred again to cover the next six months (in month 7 - July 2012). This also requires a ceteris paribus assumption of price and other variables. Consequently, the cost data transformed with a group of interventions and hand hygiene and oral health interventions looked like as in Table 1. 
A Cost-Benefit Analysis of Early Childhood Hygiene Interventions in Uzbekistan

Table 1. Transformed Cost Data on Hygiene Interventions

\begin{tabular}{|c|c|c|c|c|c|c|}
\hline Hygiene & Groups & Interventions & Month & Costs & Children & Weights \\
\hline hand & $\begin{array}{l}\text { Hygiene } \\
\text { promotion }\end{array}$ & $\begin{array}{l}\text { "Water droplet" } \\
\text { book }\end{array}$ & 1 & $34,612,500$ & 15,000 & $37.99 \%$ \\
\hline hand & Hygiene means & Liquid soap & 1 & $2,177,100$ & 964 & $2.39 \%$ \\
\hline hand & FAQ & FAQ & 1 & $1,575,000$ & 2,000 & $1.73 \%$ \\
\hline hand & $\begin{array}{l}\text { Hygiene } \\
\text { promotion }\end{array}$ & Poster & 1 & $1,455,000$ & 3,662 & $1.60 \%$ \\
\hline hand & $\begin{array}{l}\text { Hygiene } \\
\text { promotion }\end{array}$ & Poster & 1 & $1,242,266$ & 3,663 & $1.36 \%$ \\
\hline hand & $\begin{array}{l}\text { Hygiene } \\
\text { promotion }\end{array}$ & Manual pre-school & 1 & 546,250 & 964 & $0.60 \%$ \\
\hline hand & $\begin{array}{l}\text { Hygiene } \\
\text { promotion }\end{array}$ & Manual nurses & 1 & 546,250 & 5,903 & $0.60 \%$ \\
\hline hand & $\begin{array}{l}\text { Hygiene } \\
\text { promotion }\end{array}$ & Manual specialists & 1 & 546,250 & 5,904 & $0.60 \%$ \\
\hline hand & Hygiene means & Towel & 1 & 462,000 & 396 & $0.51 \%$ \\
\hline hand & Hygiene means & Liquid soap & 7 & $2,177,100$ & 964 & $2.39 \%$ \\
\hline hand & FAQ & FAQ & 7 & $1,575,000$ & 2,000 & $1.73 \%$ \\
\hline hand & Hygiene means & Towel & 7 & 462,000 & 396 & $0.51 \%$ \\
\hline oral & $\begin{array}{l}\text { Hygiene } \\
\text { promotion }\end{array}$ & $\begin{array}{l}\text { "Water droplet" } \\
\text { book }\end{array}$ & 1 & $14,137,500$ & 15,000 & $15.52 \%$ \\
\hline oral & Hygiene means & Toothbrush & 1 & $8,568,032$ & 964 & $9.41 \%$ \\
\hline oral & Hygiene means & Toothpaste & 1 & $4,601,184$ & 964 & $5.05 \%$ \\
\hline oral & $\begin{array}{l}\text { Hygiene } \\
\text { promotion }\end{array}$ & Poster & 1 & 727,500 & 3,662 & $0.80 \%$ \\
\hline oral & FAQ & FAQ & 1 & 675,000 & 2,000 & $0.74 \%$ \\
\hline oral & $\begin{array}{l}\text { Hygiene } \\
\text { promotion }\end{array}$ & Poster & 1 & 621,133 & 3,663 & $0.68 \%$ \\
\hline oral & $\begin{array}{l}\text { Hygiene } \\
\text { promotion }\end{array}$ & Manual pre-school & 1 & 182,083 & 964 & $0.20 \%$ \\
\hline oral & $\begin{array}{l}\text { Hygiene } \\
\text { promotion }\end{array}$ & Manual nurses & 1 & 182,083 & 5,903 & $0.20 \%$ \\
\hline oral & $\begin{array}{l}\text { Hygiene } \\
\text { promotion }\end{array}$ & Manual specialists & 1 & 182,083 & 5,904 & $0.20 \%$ \\
\hline oral & Hygiene means & Toothbrush & 7 & $8,568,032$ & 964 & $9.41 \%$ \\
\hline oral & Hygiene means & Toothpaste & 7 & $4,601,184$ & 964 & $5.05 \%$ \\
\hline oral & FAQ & FAQ & 7 & 675,000 & 2,000 & $0.74 \%$ \\
\hline
\end{tabular}

"Weights" column indicates the portion of costs attributed to each intervention. We derived the approximate cost-weighted number of children covered through all hygiene interventions, which is estimated at 8,719 children. This figure is applied to per-child analysis later. 
From Table 1 it can be seen that the expenditure on hand hygiene and oral health accounts for $52 \%$ and $48 \%$ of the total project expenses, respectively. Within intervention groups, the highest proportion of costs is $60 \%$ on hygiene promotion, and $35 \%$ on hygiene means. Because hygiene promotion is primarily hygiene education, as people become more 'hygiene' educated and compliance rates increase, this proportion should decline in the future and more cost could be incurred on hygiene means. Among interventions overall, the top three costs are "Water droplet" book (54\%), toothbrush (19\%), and toothpaste (10\%). While "Water droplet" books are represented both in hand hygiene and in oral health interventions, the other two biggest costs, namely toothbrush and toothpaste, are represented only in oral health means; this should indicate that oral health interventions are provided at a higher cost than hand hygiene means. In line with the previous argument, as people become more 'hygiene' educated, costs saved could be spent on oral hygiene means for the benefit of more vulnerable and 'hygiene' educated people in Uzbekistan.

The data was broken down separately for hand hygiene and oral health. Within hand hygiene groups, hygiene promotion accounts for $82 \%$ and hygiene means for only $11 \%$. On the other hand, within oral health groups, hygiene promotion accounts for $37 \%$ while hygiene means account for $60 \%$ (39\% on toothbrush and $21 \%$ on toothpaste). Oral health means are truly obtained at a higher cost and more funds could be directed to purchase them as costs reduce with people getting more 'hygiene' educated.

\subsection{Benefit Related Data}

Benefit related data comes from various sources. Macroeconomic data comes from the published reports of State Statistics Committee and the Ministry of Finance of the Republic of Uzbekistan, WHO and IMF databases. Household survey data on the cross-section of 105 children of kindergarten age was obtained from the Expert Fikri, a polling company, based on the questionnaire developed under this project.

Observed period for survey data is 2011. It covers the information about households and their income levels as well as medical costs incurred because of undergoing illnesses such as influenza, bronchitis, pneumonia, diarrhea, hepatitis A, helminthiasis, dental caries and stomatitis. Table 2 displays the summary statistics of household survey data. In particular, it shows that proportion of girls and boys surveyed is balanced. Out of 105 households, 42 households have working mothers, while 94 households have working fathers. Their average salaries have been reported at UZS 235,524 and UZS 457,213, respectively. As with the reported diseases, the proportion of respondents who actually experienced any of those eight diseases ranged from $2 \%$ for hepatitis A to $59 \%$ for influenza. 
Table 2. Summary Statistics of Household Survey Data

\begin{tabular}{lccccc}
\hline Variable name & Obs & Mean & Std. dev. & Min & Max \\
\hline Child's gender (male=1) & 105 & 0.50 & 0.50 & 0 & 1 \\
\hline Mother's monthly salary/earnings, soums & 42 & 235524 & 106338 & 60000 & 600000 \\
\hline Father's monthly salary/earnings, soums & 94 & 457213 & 229164 & 80000 & 1000000 \\
\hline $\begin{array}{l}\text { In the last 12 months, has your child been } \\
\text { sick with ...? (Yes=1) }\end{array}$ & & & & & \\
\hline influenza & 105 & 0.59 & 0.49 & 0 & 1 \\
\hline bronchitis & 105 & 0.11 & 0.32 & 0 & 1 \\
\hline pneumonia & 105 & 0.23 & 0.42 & 0 & 1 \\
\hline diarrhea & 105 & 0.25 & 0.43 & 0 & 1 \\
\hline hepatitis A & 105 & 0.02 & 0.14 & 0 & 1 \\
\hline helminthes & 105 & 0.19 & 0.39 & 0 & 1 \\
\hline caries & 105 & 0.32 & 0.47 & 0 & 1 \\
\hline stomatitis & 105 & 0.19 & 0.39 & 0 & 1 \\
\hline source:Housh
\end{tabular}

Source: Household Survey Data 2011

Income is one of the central variables in this study. We used it in computations of income saved due to avoided illness. The typical household income reported is over UZS 500,000, while median income reported is UZS 443,000 . While this skewness in income variable is consistent with the economic empirics, it implicitly shows a bias in reported incomes due to the tendency of people to underreport their incomes. Since we have a detailed questionnaire on the incidence of each disease in the last 12 months, we can calculate overall incidence of diseases. For that we have to take into account the fact that some children have been sick with the same disease twice or more. Table 3 shows, for example, although 62 families $(59 \%$ of households) reported that their children have contracted influenza-like illness in the last 12 months, in 26 households children have been sick twice or more times. So the total number of cases is 96 , which results in the incidence rate of $91.4 \%$. Incidence rates for other diseases are calculated in the same manner.

These self-reported incidence rates in Table 3 are somewhat higher than the officially reported ones. To compare, official incidence of acute respiratory illnesses among children of 3-5 years was 3.7\% countrywide 1.5\% for Tashkent city. This discrepancy may partly be explained by our methodology of accounting for ARIs that need not be confirmed in the labs.

Also, official statistics records only registered cases while there is a wide spread opinion that not many people visit doctors. The survey asked respondents who they have consulted when their child fell sick and allowed 4multiple answers: medical doctors, pharmacists, healers and others. In most cases parents have sought outside assistance. It is interesting that, in the cases of influenza, bronchitis, helminthiasis and stomatitis, number of visits to pharmacists exceeds the visits to trained doctors. This is an indication that people consult pharmacists more than trained doctors. 
Table 3. Incidence Rates of Diseases

\begin{tabular}{|c|c|c|c|c|c|c|c|c|}
\hline & 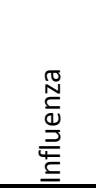 & 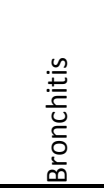 & 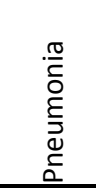 & 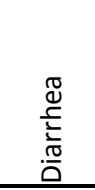 & 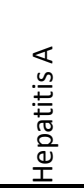 & 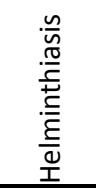 & 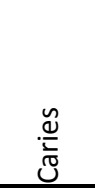 & 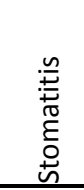 \\
\hline Number of cases & 62 & 12 & 24 & 26 & 2 & 20 & 34 & 20 \\
\hline \multicolumn{9}{|l|}{ Of which: } \\
\hline Sick two times or more & 26 & 2 & 4 & 7 & 0 & 1 & 2 & 1 \\
\hline Total number of cases & 96 & 16 & 28 & 33 & 2 & 23 & 38 & 21 \\
\hline Incidence rate & $91.4 \%$ & $15.2 \%$ & $26.7 \%$ & $31.4 \%$ & $1.9 \%$ & $21.9 \%$ & $36.2 \%$ & $20.0 \%$ \\
\hline
\end{tabular}

Source: Household Survey Data 2011

Another implication of this finding is that official statistics on incidence of diseases, which relies on number of visits to medical facilities, might significantly underestimate the true incidence. For example, out of 96 cases of influenza, in 94 cases parents sought outside assistance. But only 56 of them (58\%) consulted official medical facilities. The same difference can be seen in the case of all diseases with the exception of hepatitis $A$ and caries, which can only be treated in the specialized medical facilities.

Table 4 shows the average duration of each illness and total number of sick leaves and additional working days when parents' normal activity was affected. Average duration of each illness varies from 5 days for diarrhea, caries and stomatitis to 18 days for hepatitis $A$.

Table 4. Duration of Sickness and Sick Leaves by Parents

\begin{tabular}{|c|c|c|c|c|c|c|c|c|}
\hline Survey indicators & 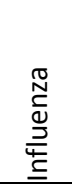 & 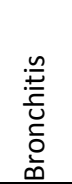 & 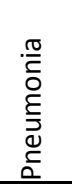 & 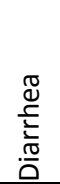 & $\begin{array}{l}\frac{1}{n} \\
\stackrel{n}{ \pm} \\
\stackrel{0}{0} \\
0 \\
0 \\
\frac{0}{1}\end{array}$ & 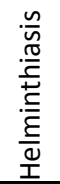 & $\frac{\mathscr{U}}{\frac{\mathscr{U}}{\pi}}$ & 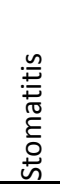 \\
\hline Average duration of sickness & 7 & 9 & 9 & 5 & 18 & 10 & 5 & 5 \\
\hline Total duration of sickness & 672 & 144 & 252 & 165 & 36 & 230 & 190 & 105 \\
\hline Total sick leaves by parents & 110 & 59 & 54 & 24 & 10 & 22 & 10 & 7 \\
\hline $\begin{array}{l}\text { Total number of additional } \\
\text { working days normal activity } \\
\text { was affected }\end{array}$ & 198 & 72 & 113 & 64 & 17 & 45 & 20 & 32 \\
\hline
\end{tabular}

Source: Household Survey Data 2011

With as many days to cure hepatitis A, total days potentially lost for hepatitis is lowest indicating its lower incidence. The table shows that diseases have significant impact on parental ability to perform everyday activities both at work and home. The loss in labor productivity is likely to be significant too, as additional working days are higher for every disease than sick leaves (Figure 2 and Figure 3). 
A Cost-Benefit Analysis of Early Childhood Hygiene Interventions in Uzbekistan

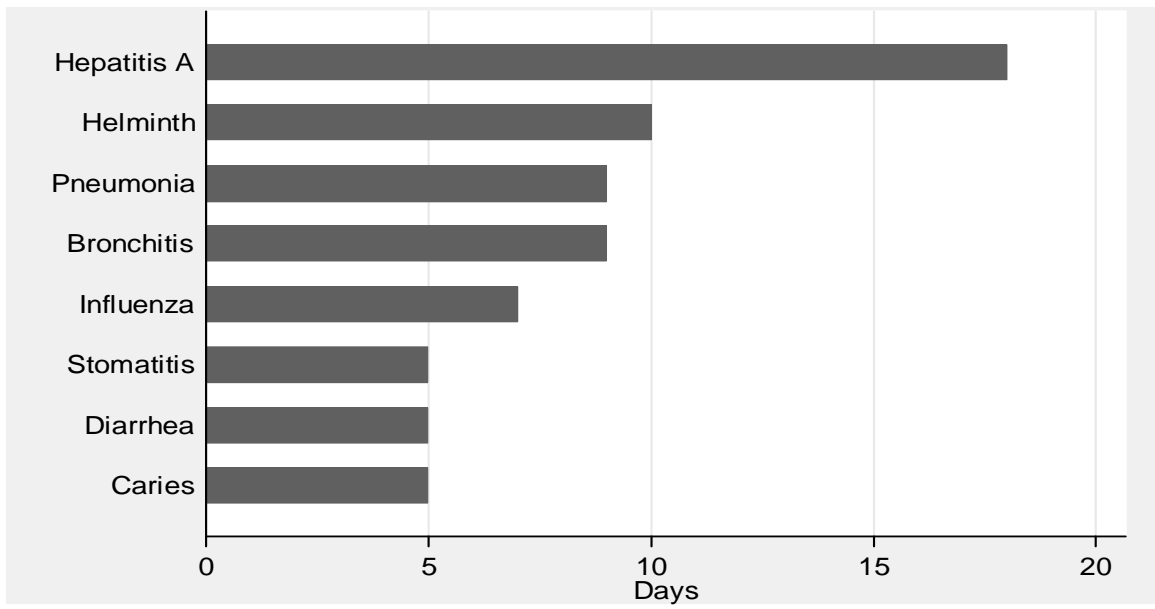

Figure 2. Average Duration of Diseases

Source: Household Survey Data 2011

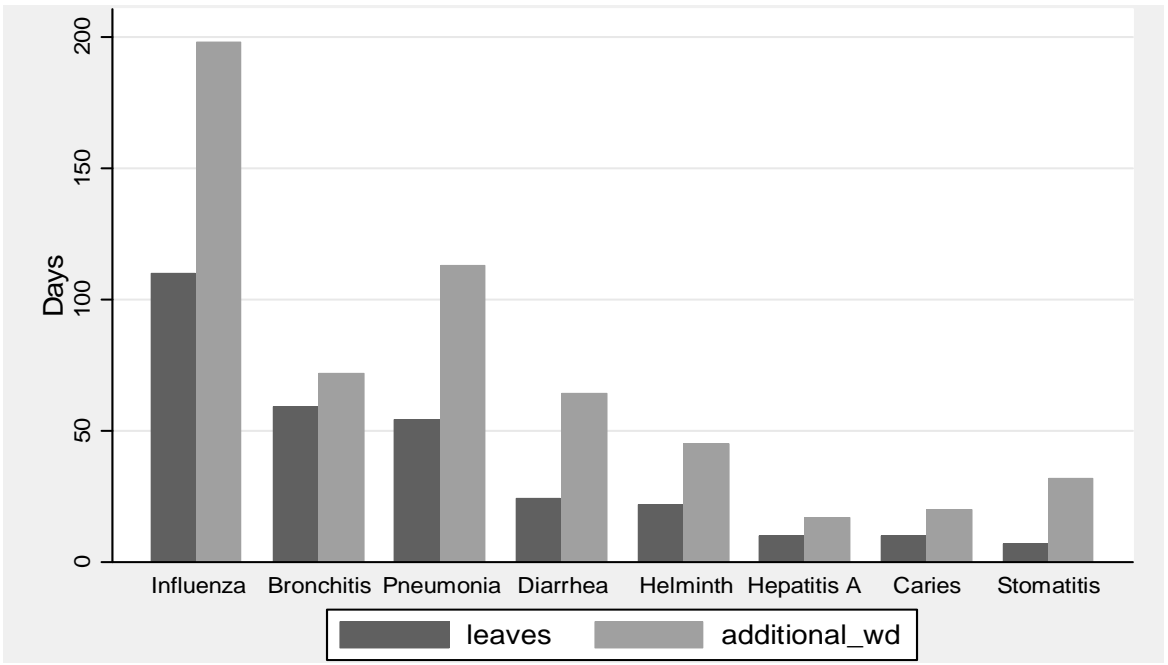

Figure 3. Total Sick Leaves and Additional Working Days by Parents

Source: Household Survey Data 2011

Table 5 depicts mean expenses households have when their children are sick. The expenses are grouped into expenses related to diagnostics, medicines, medical services and recovery therapy. The table shows that households bear significant expenses. For all diseases (with the exception of caries, where payments for medical services dominate), expenditure related to purchase of medicines and recovery therapy constitute more than $90 \%$ of all expenses. Expenses for diagnostics and medical services are comparatively low owing to the fact that the 
government usually covers costs for diagnostics and services of medical personnel. It is expected that with higher levels of commercialization of healthcare these costs will be increasingly born by households.

Table 5. Mean Expenses for Diagnostics, Medical Treatment and Services, UZS per Child

\begin{tabular}{|c|c|c|c|c|c|c|c|c|}
\hline & 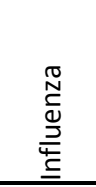 & 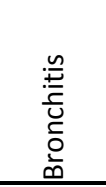 & 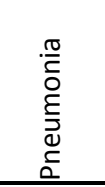 & 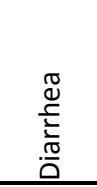 & 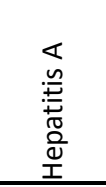 & 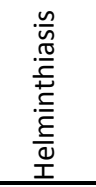 & $\frac{\mathscr{U}}{\frac{\mathscr{U}}{\pi}}$ & 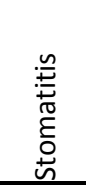 \\
\hline $\begin{array}{l}\text { Total average } \\
\text { expenses }\end{array}$ & 93,032 & 223,018 & 121,229 & 42,942 & 235,000 & 47,600 & 14,544 & 26,000 \\
\hline \multicolumn{9}{|l|}{ of which: } \\
\hline for diagnostics & 3,032 & 2,082 & 5,000 & 1,000 & - & 5,250 & - & 500 \\
\hline for medicines & 64,983 & 155,583 & 74,416 & 30,455 & 210,000 & 32,600 & - & 14,450 \\
\hline $\begin{array}{l}\text { for medical } \\
\text { services }\end{array}$ & 363 & 8,500 & 10,730 & 7,833 & - & 9,750 & 13,956 & 6,500 \\
\hline $\begin{array}{l}\text { for recovery } \\
\text { therapy }\end{array}$ & 24,654 & 56,853 & 31,083 & 3,654 & 25,000 & - & 588 & 4,550 \\
\hline
\end{tabular}

Source: Household Survey Data 2011

Household expenditure is directly related to the most common disease range from UZS 14,544 for caries treatment to UZS 235,000 for hepatitis A treatment. Most frequent ARI (influenza, bronchitis and pneumonia) require highest level of spending. Second most frequent diseases - intestinal contagious diseases (diarrhea, hepatitis $A$ and helminthiasis) - also require significant resources for treatment. However, lower incidence rates of these diseases also mean lower expenditure. Although oral cavity disease (caries and/or stomatitis) has higher probability of occurrence, the expenditure per child is moderate that do not put much strains on household budgets.

\subsection{CBA Methodology}

We employ standard CBA methodology that requires monetizing all health impacts by determining consumers' willingness to trade income (or wealth) for the health improvements or a reduction in morbidity risk. We measure direct, indirect and intangible costs and benefits. To compare costs with benefits, we have to discount benefits since they accrue in the future and are therefore worth less in present terms, while the costs are incurred immediately.

To fully account for intangible costs and benefits in the analysis, we utilize shadow pricing method where intangibles are assigned values. Although shadow prices are often unavailable and frequently controversial, they have the advantage of allowing economic comparisons with programs or policies outside the health 
sector. The proper decision rule is to select projects with the highest net benefits: total social benefits less total social costs.

Shadow values can be elicited using different approaches. In this study we use costof-illness (COI) approach that captures both the financial and economic costs of being ill. COI estimates are available for a number of illnesses in a number of populations, and provide an uncontroversial measure of the economic benefits of avoiding an illness. Public COI refers to the cost incurred by the public sector health system in treating an illness, such as staff salaries, publicly provided treatments, capital costs of facilities, etc. Private $\mathrm{CO}$ measures financial and economic costs incurred by patients (i.e. lost work days, cost of medicines not covered by the public system, etc). In a CBA framework, ex ante $\mathrm{COI}$ (COI weighted by the probability of falling ill) is compared with the costs of reducing the illness.

Along with the market rate of interest to discount the costs and benefits, we utilize the social discount rate (which includes the preferences of future generations) for discounting the net-benefit stream. The rationale for using the social discount rate is to calculate the net present value of a project's social costs and benefits over time. A positive net present value indicates the project increases efficiency or raises wealth: it produces enough benefits to fully compensate individuals for the forgone benefits of the resources it displaces from alternative uses.

We also make several simplifying assumptions when comparing base year (2011) with following period ( 2012 and beyond): a) the distribution of household incomes does not change over time; b) the probability of diseases is constant over time; c) Benefit and cost cash flows are generated over one-year horizon. While both benefits and costs may naturally generate cash flows beyond 2012, those are assumed insignificant and thus ignored.

We calculate total benefits as a sum of three components:

1. Medical costs avoided due to illness risk reduction

2. Income saved due to illness risk reduction

3. Budget resources saved due to illness risk reduction.

All the three components are expected to generate cash flows in a year to come. Moreover, as the period under consideration is only one year, these cash flows are discounted into a current month and year, December 2011. The choice of discount rate is ambiguous in the literature; the matter of using appropriate discount rates is still unresolved. With this uncertainty involved, expert opinions may differ on the "right" prices or other assumptions regarding effects. For this reason, we opt to do sensitivity analyses for both benefits and costs at discount rates ranging from $6 \%$ to $24 \%$ in increments of 2 percentage points, candidates for social discount rate. Moreover, the recent evidence shows while exponential discounting is a frequently employed method because of its more accurate capture of time preferences. However, this method places lower weights for near future cash flows and higher weights for distant future cash flows. This is inappropriate due to the limitation in 
time period under this project and thus used constant exponential discounting method to discount future cash flows under each benefit component.

\subsubsection{Medical Costs Avoided due to Illness Risk Reduction}

When a child falls sick, parents will have to incur costs for medical treatment. The case with health insurance policy results in the same conclusion in the sense the cost cash flows at any rate will be generated. With hand hygiene and oral health interventions, the incidence rate of a disease is expected to fall and, as a result, parents will avoid medical treatment costs due to illness.

Medical costs avoided due to the reduction in disease incidence were calculated using the following formula:

$$
\text { Costs avoided }=\sum_{k} \sum_{j} T C_{j} \cdot \frac{1}{\left(1+\frac{r}{12}\right)^{n}} \cdot d_{k}
$$

whereTC is medical treatment costs incurred, $d_{k}$ is the reduction in incidence rate of disease $k$ (Figure 4), $j$ is the household identity, $r$ is an annual discount rate, and $n$ is the number of months to Dec 2011.

Household survey data contains 3variables to capture the medical costs incurred, which were added, after each $T C$ has been accurately discounted. Moreover, this calculation provides the pecuniary measure of medical costs avoided for the sample of 105 children. This estimate is adjusted for 8719 children to compute benefits (per child) resulting from costs avoided. Finally, adjusted costs avoided were calculated for $r$ ranging from $6 \%$ to $24 \%$ with 2 ppt increase in each trial.

\subsubsection{Income Saved due to Illness Risk Reduction}

When a child falls sick, the circumstances are that at least one parent looks after the child depending on the seriousness of a disease. Even when only one parent is involved, the other parent will have his or her attention drawn on the child treatment. We used this argument to approximate the income variable as the average income of both parents. The distribution of the income is depicted in Figure 5. It is this income that measures the labor productivity of parents and that could be lost due to child's sickness. With hand hygiene and oral health interventions, the incidence rate of a disease is expected to fall by the rates described in the literature review and depicted in Figure 5. This also results in both parents less frequently submitting sickness leaves to their respective employers and the resultant income saved will present a benefit cash flow. 
A Cost-Benefit Analysis of Early Childhood Hygiene Interventions in Uzbekistan

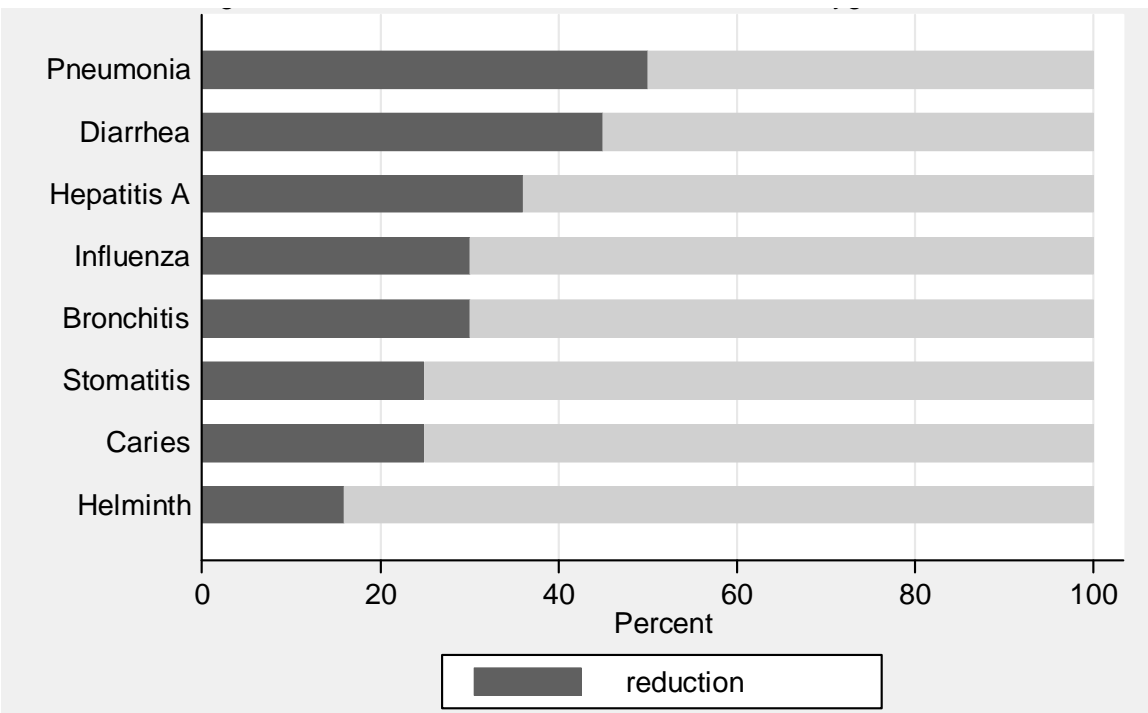

Figure 4. Reduction in illness Incidence due to Hygiene Interventions Source: Household Survey Data 2011

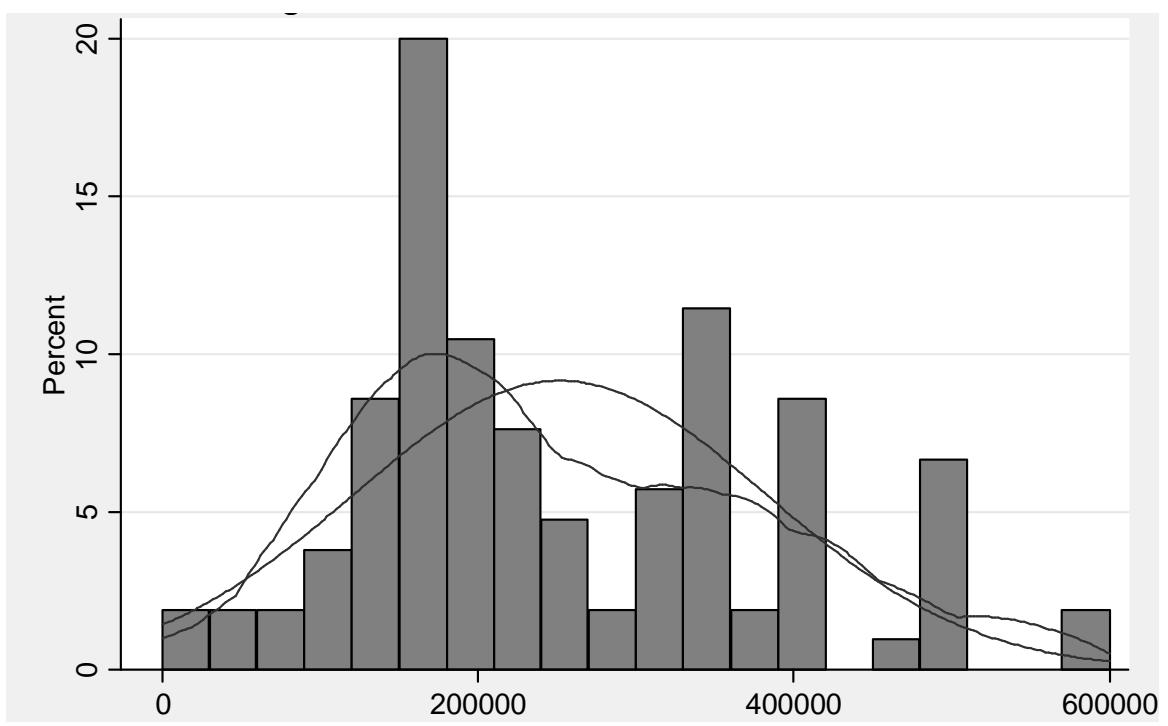

Figure 5. Household Income Distribution Source: Household Survey Data 2011 
Not considering month variables, household survey contains two variables to capture the number of days lost, $D L$, due to falling sick by the child. We employed the following formula to calculate income saved due to risk reduction of illness:

$$
\text { Income saved }=\sum_{k} \sum_{j} \frac{I N C_{j}}{30} \cdot D L_{j} \cdot \frac{1}{(1+r / 12)^{n}} \cdot \omega_{k} \text { and } \omega_{k}=\frac{\sum_{k} \sum_{j} T C_{j}}{\sum_{k} \sum_{j} T C_{j k}} \cdot d_{k}
$$

where $T C_{j k}$ denotes treatment costs incurred by household $j$ for disease $k$.

It should be mentioned that (a) division by 30 and multiplication by $D L$ serves as a proxy for the days lost as a result of illness in monetary terms; (b) $\omega_{k}$ provides overall average weight of risk reduction for each disease $k$ (Table 6); (c) this calculation provides a monetary measure of medical costs avoided for the sample of 105 children. This estimate should be, again, adjusted for 8,719 children to compute total benefits resulting from income saved, and (4) income saved due to risk reduction of illness has been calculated for $r$ ranging from $6 \%$ to $24 \%$ with 2 ppt at each trial.

\subsubsection{Budget Resources Saved due to Illness Risk Reduction}

Uzbekistan has a socially oriented government and has a considerable portion of its state budget allocated to health care. In Tashkent city, health care costs was set at UZS 17083.81 per person. With hand and oral hygiene interventions, the incidence rate of a disease is expected to fall and, as a result, budget resources will be saved. However, the disease risk reduction has been adjusted taking into consideration the budget allocation is done before the financial year starts:

$$
\text { Resources saved }=17,083.81 \cdot \frac{\omega_{k}}{(1+r / 12)^{12}}
$$

If the allocation of state budget remains at UZS 17,083.81 per person in Tashkent, this amount is discounted to a year base period for values of $r$ ranging from $6 \%$ to $24 \%$ at 2 ppt increase at each trial.

\section{Results}

In line with previous discussion, benefits are derived using COI approach and consist of the following: (i) income saved by parents due to risk reduction in the incidence of disease; (ii) reduction in medical costs due to avoided illness; and (iii) budget resources saved. On the other hand, costs are project expenditure the project has spent on hygiene promotion activities in the pilot kindergartens in 2011.

Bringing both costs and benefits into a common denominator requires the use of discount rates. We considered three issues that urge to modify the simple net present value (NPV) rule: in the absence of risk, any project with a positive NPV 
calculated using shadow-prices and discounting at the market interest rate will contribute to economic efficiency.

Firstly, the social time preference reflects the view that the market interest rate does not fully reflect society's preference for present as opposed to future consumption, and that a discount rate based on a social time preference rate should be used to calculate NPV from a public interest viewpoint. The social time preference rate tends to be lower than the market interest rate. Secondly, the social opportunity cost is based on the notion that, because of tax-induced distortions to the pattern of resource allocation, the opportunity cost to the economy of raising public funds for government expenditures is higher than the nominal amount raised. This suggests that a public project should have a present value of benefits sufficiently large not only to offset project costs, but also to offset the premium on the cost of public funds if the project is to make a net contribution to efficiency. Thirdly, the fact that a project has a positive NPV does not necessarily imply that now is the most efficient time to implement it. Because additional information about the project variables - prices, costs etc. - may accrue in the future there could be an advantage to keeping open the option of undertaking the project. Once this option has been exercised it ceases to have any value, and the loss of option value should be taken into account in the decision to proceed.

Estimation results of costs and benefits of hand hygiene and oral health intervention are presented in Table 6. As can be seen from the table, benefits outweigh costs at each discount rate level considered. At its lowest level of 6\%, total benefits outweigh total costs and make NPV over UZS $87 \mathrm{~m}$. Taking into consideration that these benefits cover 8,719 children $^{1}$, net benefits that accrue to each child is above UZS 10,000 . On the other hand, the second measure of intervention efficacy is the benefit-cost ratio. For a $6 \%$ discount it equals 1.97 , implying the return of $97 \%$ per UZS invested per child. For $8 \%$ discount rate, it can be seen that the total and per child benefits outweigh total and per child costs by almost UZS $60 \mathrm{~m}$ and UZS 6,700, respectively. Benefit-cost ratio of 1.68 implies that per UZS 1000 spent on hand hygiene and oral health per year has a return of UZS 1680 , implying a $68 \%$ increase. As we continue in this fashion, an increase in discount rate to $24 \%$ in 2 percentage points is associated with a declining NPV and benefit-cost ratios. However, values of NPV and benefit-cost ratios are negatively related to discount rates.

While positive NPV and benefit-cost ratio above unity and a good sign that hand hygiene and oral health interventions must be made, there is other measure to consider - the internal rate of return (IRR). Most CBA also summarize outcomes in terms of the internal rate of return (IRR), which is the discount rate when applied to the incremental net income that produces a zero NPV.

\footnotetext{
${ }^{1}$ Number of children covered is the number of children weighted by the costs related to hygiene promotion.
} 


\begin{tabular}{|c|c|c|c|c|c|c|c|c|c|c|}
\hline \multicolumn{11}{|c|}{ Cost-weighted number of children covered: 8719} \\
\hline Discount Rates & $6 \%$ & $8 \%$ & $10 \%$ & $12 \%$ & $14 \%$ & $16 \%$ & $18 \%$ & $20 \%$ & $22 \%$ & $24 \%$ \\
\hline Total Benefits & $177,436,436$ & $148,276,008$ & $129,852,829$ & $117,054,699$ & $107,565,264$ & $100,189,082$ & $94,247,011$ & $89,324,325$ & $85,153,370$ & $81,553,584$ \\
\hline \begin{tabular}{|l|} 
Income saved due to \\
illness risk reduction \\
\end{tabular} & $46,290,987$ & $34,957,916$ & $27,925,178$ & $23,153,896$ & 19,714,906 & $17,126,078$ & 15,112,222 & $13,504,689$ & $12,194,377$ & 11,107618 \\
\hline \begin{tabular}{|l|} 
Medical costs \\
\end{tabular} & $79,250,609$ & $62,630,164$ & $52,448,303$ & $45,606,304$ & $40,707,501$ & $37,035,494$ & $34,185,944$ & $31,913,586$ & $30,061,203$ & $28,523,454$ \\
\hline \begin{tabular}{|l} 
Adjusted budget \\
resources
\end{tabular} & $51,894,841$ & $50,687,928$ & $49,479,348$ & $48,294,498$ & $47,142,857$ & $46,027,510$ & 44,948844 & $43,906,050$ & $42,897,790$ & $41,922,511$ \\
\hline Total Costs & $90,064,185$ & $88,437,454$ & $86,8427,24$ & $85,279,313$ & $83,746,556$ & $82,243,803$ & 80,77042 & 79,325784 & \begin{tabular}{|l|}
77,90929 \\
\end{tabular} & 76,520344 \\
\hline Net benefits & $87,372,250$ & \begin{tabular}{|l|}
$59,838,553$ \\
\end{tabular} & $43,010,105$ & $31,775,386$ & $23,818,707$ & $17,945,279$ & 13,476591 & $9,998,541$ & \begin{tabular}{|l|}
$7,244,080$ \\
\end{tabular} & $5,033,240$ \\
\hline Benefits per child & 20,351 & 17,006 & 14,893 & 13,425 & 12,337 & 11,491 & 10,809 & 10,245 & 9,766 & 9,354 \\
\hline \begin{tabular}{|l|} 
Income saved due to \\
illness risk reduction \\
\end{tabular} & 5,309 & 4,009 & 3,203 & 2,656 & 2,261 & 1,964 & 1,733 & 1,549 & 1,399 & 1,274 \\
\hline \begin{tabular}{|l|} 
Medical costs \\
avoided
\end{tabular} & 9,089 & 7,183 & 6,015 & 5,231 & 4,669 & 4,248 & 3,921 & 3,66 & 3,448 & 3,271 \\
\hline \begin{tabular}{|l} 
Adjusted budget \\
resources
\end{tabular} & 5,952 & 5,814 & 5,675 & 5,539 & 5,407 & 5,279 & 5,155 & 5,036 & 4,92 & 4,808 \\
\hline Costs per child & 10,33 & 10,143 & 9,96 & 9,781 & 9,605 & 9,433 & 9,264 & 9,098 & 8,936 & 8,776 \\
\hline $\begin{array}{l}\text { Net Benefits per } \\
\text { Child }\end{array}$ & 10,021 & 6,863 & 4,933 & 3,644 & 2,732 & 2,058 & 1,546 & 1,147 & 831 & 577 \\
\hline Benefit / Cost Ratio & 1.97 & 1.68 & 1.50 & 1.37 & 1.28 & 1.22 & 1.17 & 1.13 & 1.09 & 1.07 \\
\hline
\end{tabular}


The criterion here that the social discount rate chosen from the available discount rates requires IRR be greater than the social discount rate. Figure 6 shows that NPV decreases as discount rate increases, but never goes to zero within specified discount rate range. Thus for any given level of discount rate, IRR appears to be higher the social discount rate. This means that both net benefits as well as returns to the intervention are positive.

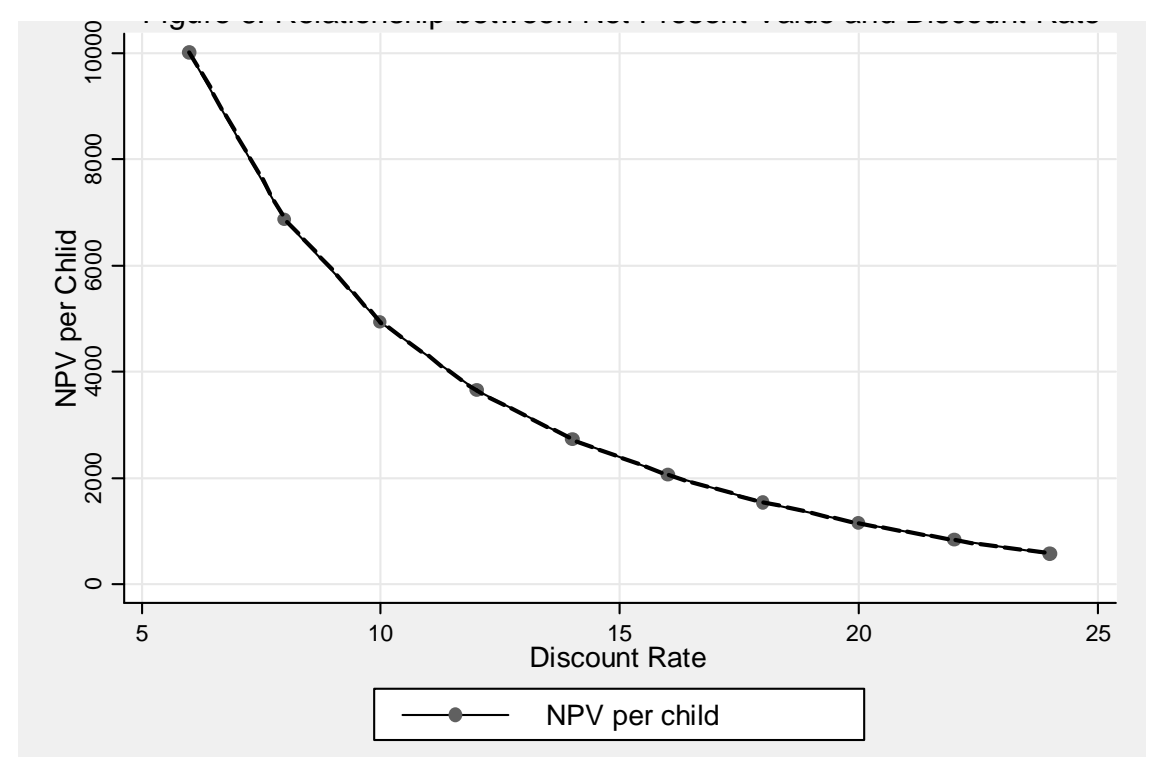

Figure 6. Relationship between Net Present Value and Discount Rate

The results show that it is within a large range of assumptions and discount rates, hand washing and tooth brushing interventions are economically efficient and socially desirable. The estimates of economic efficiency might be even underestimated since we make two simplifying assumptions: time horizon for benefits calculation is only 1-2 years and due to lack of data we assume that interventions will have an impact solely on morbidity (incidence rates of diseases), not on mortality and disability rates.

Due to the lack of original observational or intervention data, we have decided to rely on the effectiveness of studies conducted in other countries. Our results crucially rely on the assumption that compliance with hand and oral cavity hygiene is close to $100 \%$. We could not find reliable data on the relationship between varying compliance rates and reduction in the risk of specific illness. It is clear that if compliance is lower, effectiveness of hygiene promotion campaign for prevention of diseases will be lower too. 
Despite methodological limitations, our study shows that hygiene interventions other than infrastructure implementation are important for preventing infections. While these results may not be surprising or "new", they are nevertheless impressive and important because they demonstrate that in Uzbekistan incidence of communicable diseases can be drastically reduced by cost-efficient preventive measures such as hand washing and tooth brushing.

Our results have important policy implications for the health care system in Uzbekistan. First, it is necessary to make improved hand hygiene adherence a national priority and consider provision of a funded, coordinated implementation program while ensuring monitoring and long-term sustainability. Hygiene promotion like any other health intervention is subject to economies of scale - the larger the intervention the higher benefits due to the economies of scale and positive externalities associated with better health and nutrition. Second, it is necessary to strengthen infection control capacities within health-care settings. Health care facilities should be re-oriented from curing diseases to preventing them. Third, hand hygiene should be promoted at the community level to strengthen both self-protection and the protection of others. Only full-fledged participation of health care officials, teachers and parents will ensure success of hygiene promotion activities. And fourth, use of hand hygiene and oral health as a quality indicator in health-care settings should be encouraged. This also stipulates development and adoption of new set of indicators as well as tools for monitoring and evaluation of these indicators.

\section{Conclusion}

Health interventions can affect the incidence of disease, the case-fatality rate, or the degree of disability. Preventive health interventions, considered in this paper, are primarily designed to affect the incidence of disease. This study also attempted to quantify and compare all costs and benefits of hand washing and tooth brushing for kindergarten age children in Tashkent city.

The results of this study have several implications for policymakers. First, comparison of official statistics on disease incidence rates with similar estimates obtained from the household survey indicates that official statistics might underestimate the incidence rates of almost every major illness. The discrepancy between official statistics and survey statistics can probably be partly explained by the fact that not every person seeks assistance from qualified medical doctors when child becomes sick. For many diseases, visits to pharmacists outweigh visits to doctors, indicating the level of trust in doctors is low.

Cost-benefit analysis shows that benefits outweigh costs at each discount rate level considered. At its lowest level of $6 \%$, benefit-cost ratio equals 1.97 , implying the return of $97 \%$ per child. Benefit-cost ratio when discount rate is equal to $24 \%$ is 1.07 that indicates that benefits still outweigh costs and corresponding rate of return on the project is $7 \%$. 
Though it is often difficult to attribute a specific hygiene intervention to a reduction in specific illness, our study has shown that prevention of disease through hygiene promotion is cost-effective. To be the most effective, hygiene interventions should contain many interrelated interventions aimed at educating teachers, parents and children, as well as ensuring that necessary means such as soaps and toothpastes are available.

Our results have important policy implications for the health care system in Uzbekistan. First, it is necessary to make improved hand hygiene adherence a national priority and consider provision of a funded, coordinated implementation program while ensuring monitoring and long-term sustainability. Second, it is necessary to strengthen infection control capacities within health-care settings. Third, hand hygiene should be promoted at the community level to strengthen both self-protection and the protection of others. And fourth, use of hand hygiene as a quality indicator in health-care settings should be encouraged.

\section{References}

Acharya, A, and M Paunio. Environmental Health and Child Survival; Epidemiology, Economics, Experiences. Washington DC: The World Bank (Environment Department), 2008.

Adhikari, Ramesh, Paul Gertler, and Anneli Lagman. Economic Analysis of Health Sector Projects - A Review of Issues, Methods, and Approaches. Manila: ADB, 1999.

Ansari, SA, S Springthorpe, SA Sattar, S Rivard, and M Rahman. "Potential role of hands in the spread of respiratory viral infections: studies with human parainfluenza virus 3 and rhinovirus 14." Journal of Clinical Microbiology 29, 1991: 2115-2119.

Barker, DJP. Mothers, Babies and Health in Later Life. Edinburgh: Churchill Livingstone, 1998.

Black, RE, SS Morris, and J Bryce. "Where and why are 10 million children dying every year?" Lancet 361, 2003: 2226-2234.

http://dx.doi.org/10.1016/S0140-6736(03)13779-8

Bloomfield, S.E, and E. A. Scott. "Developing an effective policy for home hygiene: a riskbased approach." International Journal of Environmental Health Research 13 (1), 2003: S57s66.

http://dx.doi.org/10.1080/0960312031000102804

Borghi, J, L Guinness, J Ouedraogo, and V Curtis. "Is hygiene promotion cost-effective? A case study in Burkina Faso." Tropical Medicine \& International Health, 2002: 7, 1-10. http://dx.doi.org/10.1046/j.1365-3156.2002.00954.x

Borghi, J., L. Guinness, J. Ouedraogo, and V. Curtis. "Is hygiene promotion cost-effective? A case study in Burkina Faso." Tropical Medicine and International Health 7(11), 2002: 960969.

http://dx.doi.org/10.1046/j.1365-3156.2002.00954.x

Cairncross, Sandy. "Handwashing with soap - a new way to prevent ARIs?" Tropical Medicine and International Health, August 2003: 8: 677-679.

http://dx.doi.org/10.1046/j.1365-3156.2003.01096.x 
Churchill, AA, D de Ferranti, R Roche, C Tager, and AA Walters. Rural water supply \& sanitation; time for a change. World Bank Discussion Paper No. 18, Washington DC: The World Bank, 1987.

Cost, Quality and Outcomes in Child Care Centers. Denver, Colorado: University of Colorado at Denver, 1995.

Curtis, V, B Kanki, S Cousens, and et al. "Evidence for behaviour change following a hygiene promotion programme in West Africa." Bulletin of the World Health Organization, 2001: 79.

Curtis, V, L Danquah, and R Aunger. "Planned, motivated and habitual hygiene behaviour: an eleven country review." Health Educ Res 24, 2009: 655-673. http://dx.doi.org/10.1093/her/cyp002

Curtis, V., and S. Cairncross. "Effect of washing hands with soap on diarrhoea risk in the community: a systematic review." Lancet Infect Dis, 2003: 3: 275-81. http://dx.doi.org/10.1016/S1473-3099(03)00606-6

Curtis, V.A., S. Cairncross, and R. Yonli. "Domestic hygiene and diarrhoea, pinpointing the problem." Tropical Medicine and International Health, 5(1), 2000: 22-32. http://dx.doi.org/10.1046/j.1365-3156.2000.00512.x

Dyer, DL, A. Shinder, and F. Shinder. "Alcohol-free instant hand sanitizer reduces elementary school illness absenteeism." Family Medicine, 2000: 32, 633-638.

Esrey, S. A., R. G. Feachem, and J. M. Hughes. "Interventions for the Control of Diarrhoeal Diseases among Young Children: Improving Water Supplies and Excreta Disposal Facilities." WHO Bulletin, 1985: 63(4): 757-772.

Fung, IC, and S Cairncross. "Ascariasis and handwashing." Trans R Soc Trop Med Hyg 103, 2009: 215-222.

http://dx.doi.org/10.1016/j.trstmh.2008.08.003

Greenwood, Peter. Costs and Benefits of Early Childhood Intervention. Santa Monica, California: Office of Juvenile Justice and Delinquency Prevention, 1999.

Guerrant, RL, and BL Blackwood. "Threats to global health and survival: the growing crises of tropical infectious diseases - our 'unfinished agenda'." Clinical Infectious Diseases, 1999: 28, 966-986.

http://dx.doi.org/10.1086/514765

Guyer, Bernard, Sai Ma, Holly Grason, Kevin Frick, Deborah Perry, and Alyssa Wigton. Investments to Promote Children's Health: a Systematic Literature Review and Economic Analysis of Interventions in the Preschool Period. Baltimore, MD: Women's and Children's Health Policy Center: John Hopkins Bloomberg School of Public Health, 2008.

Gwaltney, Jr JM, PB Moskalski, and JO Hendley. "Hand-to-hand transmission of rhinovirus colds." Annals of Internal Medicine 88, 1978: 463-467.

http://dx.doi.org/10.7326/0003-4819-88-4-463

Gwaltney, Jr JM, PB Moskalski, and JO Hendley. "Interruption of experimental rhinovirus transmission." The Journal of Infectious Diseases 142, 1980: 811-815. http://dx.doi.org/10.1093/infdis/142.6.811

Harris, R., A.D Nicoll, P.M. Adair, and C.M. Pine. "Risk factors for dental caries in young children: a systematic review of the literature." Community Dental Health (2004) 21 (Supplement), 2004: 71-85. 
Hendley, JO, RP Wenzel, and JM Gwaltney. "Transmission of rhinovirus colds by selfinoculation." The New England Journal of Medicine 288, 1973: 1361-1364. http://dx.doi.org/10.1056/NEJM197306282882601

Holt, R.D., G.B. Winter, M.C. Downer, W.J. Bellis, and I.S. Hay. "Caries in pre-school children in Cambden 1993/94." British Dental Journal 181, 1996: 405-410. http://dx.doi.org/10.1038/sj.bdj.4809277

Hutton, G, and L Haller. Evaluation of the costs and benefits of water and sanitation improvements at the global level. WHO/SDE/WSH/04.04, Geneva: World Health Organization, 2004.

Hutton, G, L Haller, and J Bartram. "Global Cost-Benefit Analysis of Water Supply and Sanitation Interventions." J Water Health 5, 2007: 481-502. http://dx.doi.org/10.2166/wh.2007.009

lyer, Param, and Jennifer Sara. "The Handwashing Handbook." The World Bank Group. www.worldbank.org (accessed December 1, 2011).

Khan, MU. "Interruption of shigellosis by handwashing." Transactions of the Royal Society of Tropical Medicine and Hygiene , 1982: 76, 164-168.

http://dx.doi.org/10.1016/0035-9203(82)90266-8

Landrigan, PJ, CB Schechter, JM Lipton, MC Fahs, and J Schwartz. "Environmental Pollutants and Disease in American Children: Estimates of Morbidity, Mortality, and Costs for Lead Poisoning, Asthma, Cancer, and Developmental Disabilities." Environmental Health Perspectives 110 (7), 2002: 721-728.

http://dx.doi.org/10.1289/ehp.02110721

Laxminarayan, R, J Chow, and SA Shahid-Salles. Intervention Cost-Effectiveness: Overview of Main Messages. In: Jamison DT, Breman JG, Measham AR, et al., editors. Disease Control Priorities in Developing Countries. 2nd edition, Washington DC: The World Bank, 2006.

Luby, SP, et al. "Effect of handwashing on child health: a randomised controlled trial." Lancet Jul 16-22; 366(9481), $2005:$ 225-33.

Master, D, Longe Hess, and H. Dickson. "Scheduled hand washing in an elementary school population." Family Medicine, 1997: 29(5): 336-9.

Murray, CJ.L. "Rational approaches to health priority setting in international health." Journal of Tropical Medicine and Hygiene, Volume 93, 1990.

Murray, CJL, and AD Lopez. "Global mortality, disability and the contribution of risk factors: global burden of disease study." Lancet, 1997: 349, 1436-1442. http://dx.doi.org/10.1016/S0140-6736(96)07495-8

Pinfold, JV, and NJ Horan. "Measuring the effect of a hygiene behaviour intervention by indicators of behaviour and diarhoeal disease." Transactions of the Royal Society of Tropical Medicine and Hygiene, 1996: 90, 366-371.

Pita-Fernández, S, A Pombo-Sánchez, J Suárez-Quintanilla, S Novio-Mallón, B Rivas-Mundiña, and S Pértega-Díaz. "Clinical relevance of tooth brushing in relation to dental caries." [In Spanish], Aten Primaria, 42(7), 2010: 372-9. http://dx.doi.org/10.1016/j.aprim.2009.10.014

Rand. Investing in Our Children: What We Know and Don't Know About the Costs and Benefits of Early Childhood Interventions. Washington, D.C.: Rand, 1998. 
Reed, SE. "An investigation of the possible transmission of rhinovirus colds through indirect contact." The Journal of Hygiene 75, 1975: 249-258. http://dx.doi.org/10.1017/S0022172400047288

Rubin, I., J. Nodvin, RJ Geller, WG Teague, BL Holtzclaw, and El Felner. "Environmental Health Disparities: Environmental and Social Impact of Industrial Pollution in a Community the Model of Anniston, AL." Pediatric Clinics of North America, 54(2), 2007: 375-98. http://dx.doi.org/10.1016/j.pcl.2007.01.007

Ryan, MAK, RS Christian, and J Wohlrabe. "Handwashing and respiratory illness among young adults in military training." American Journal of Preventive Medicine, 2001: 21, 79-83. http://dx.doi.org/10.1016/S0749-3797(01)00323-3

Sanctuary, M, H Tropp, and L Haller. Making Water a Part of Economic Development. Stockholm: Stockholm International Water Institute and World Health Organization for the Commission on Sustainable Development, 2004.

Schmidt, WP, S Cairncross, ML Barreto, T Clasen, and B Genser. "Recent diarrhoeal illness and risk of lower respiratory infections in children under the age of 5 years." Int J Epidemiol., 2009: 159.

Schwarz, E., E.C.M. Lo, and M.C.M. Wong. "Prevention of early childhood caries - results of a fluoride toothpaste demonstration trial on Chinese preschool children after three years." Journal of Public Health Dentistry 58, 1998: 12-18.

http://dx.doi.org/10.1111/j.1752-7325.1998.tb02985.x

Sedgwick, WT, and S Macnutt. "An Examination of the Theorem of Allen Hazen that for every Death from Typhoid Fever Avoided by the Purification of Public Water Supplies, Two or Three Deaths are Avoided from other Causes." Science 28, 1908: 215-216. http://dx.doi.org/10.1126/science.28.711.215

St Sauver, J, M Khurana, A. Kao, and B Foxman. "Hygienic practices and acute respiratory illness in family and group day care homes." Public Health Reports, 1998: 113, 544-551.

Stanton, BF, and JD Clemens. "An Educational Intervention for Altering Water-Sanitation Behaviors to Reduce Childhood Diarrhea in Urban Bangladesh: part II a randomised trial to assess the impact of the intervention on hygienic behaviors and rate ofdiarrhea." American Journal of Epidemiology, 1987: 125, 292-333.

The Future of Children: Long-Term Outcomes of Early Childhood Programs. Los Altos, California: The Center for the Future of Children, The David and Lucille Packard Foundation, 1995.

The World Bank: Benefits of Early Child Development Programs. http://go.worldbank.org/2AHNORUYEO (accessed November 15, 2011).

UNICEF. Tashkent: UNICEF in Uzbekistan, 2007.

WHO. Global Health Observatory. 2008 . http://www.who.int/gho/child_health/mortality/mortality_causes_text/en/index.html (accessed December 15, 2011).

WHO. Reducing risks, promoting healthy life. The World Health Report 2002, Geneva: WHO, 2002, p. 230.

WHO (2002). Reducing Risks, Promoting Healthy Life. The World Health Report, Geneva.

Ye, W., X.P. Feng, and Y.L. Liu. "Epidemiological study of the risk factors of rampant caries in Shanghai children." Chinese Journal of Dental Research 2, 1999: 58-62. 